\title{
Strong Convergence Theorems for Asymptotically Nonexpan- sive Mappings by Hybrid Methods
}

\author{
XIAOLONG QIN \\ Department of Mathematics, Tianjin Polytechnic University, Tianjin 300160, \\ China \\ e-mail : qxlxajh@163.com \\ YONGFU SU \\ Department of Mathematics, Tianjin Polytechnic University, Tianjin 300160, \\ China \\ e-mail : suyongfu@tjpu.edu.cn

\section{MeiJuAn SHang} \\ Department of Mathematics, Tianjin Polytechnic University, Tianjin 300160, \\ China \\ Department of Mathematics, Shijiazhuang University, Shijiazhuang 050035, China \\ e-mail : meijuanshang@sina.com
}

AbSTRACT. In this paper, we prove two strong convergence theorems for asymptotically nonexpansive mappings in Hibert spaces by hybrid methods. Our results extend and improve the recent ones announced by Nakajo, Takahashi [K. Nakajo, W. Takahashi, Strong convergence theorems for nonexpansive mappings and nonexpansive semigroups, J. Math. Anal. Appl. 279 (2003) 372-379], Kim, Xu [T. H. Kim, H. K. Xu, Strong convergence of modified mann iterations for asymptotically nonexpansive mappings and semigroups, Nonlinear Anal. 64 (2006) 1140-1152], Martinez-Yanes, Xu [C. Martinez-Yanes, H. K. Xu, Strong convergence of the CQ method for fixed point iteration processes, Nonlinear Anal. 64 (2006) 2400-2411] and some others.

\section{Introduction and preliminaries}

Let $H$ be a real Hilbert space, $C$ a nonempty closed convex subset of $E$, and $T: C \rightarrow C$ a mapping. Recall that $T$ is nonexpansive if

$$
\|T x-T y\| \leq\|x-y\| \quad \text { for all } x, y \in C,
$$

and $T$ is asymptotically nonexpansive [2] if there exists a sequence $\left\{k_{n}\right\}$ of positive

Received January 8, 2007, and in revised form, March 10, 2007.

2000 Mathematics Subject Classification: 47H09, 47H10.

Key words and phrases: Asymptotically nonexpansive mapping, Hilbert space, nonexpansive mapping, fixed point. 
real numbers with $\lim _{n \rightarrow \infty} k_{n}=1$ and such that

$$
\left\|T^{n} x-T^{n} y\right\| \leq k_{n}\|x-y\| \quad \text { for all } n \geq 1 \text { and } x, y \in C .
$$

A point $x \in C$ is a fixed point of $T$ provided $T x=x$. Denote by $F(T)$ the set of fixed points of $T$; that is, $F(T)=\{x \in C: T x=x\}$.

Some iteration processes are often used to approximate a fixed point of a nonexpansive mapping $T$. The first iteration process is now known as Mann's iteration process [8] which is defined as

$$
x_{n+1}=\alpha_{n} x_{n}+\left(1-\alpha_{n}\right) T x_{n}, \quad n \geq 0,
$$

where the initial guess $x_{0}$ is taken in $C$ arbitrarily and the sequence $\left\{\alpha_{n}\right\}_{n=0}^{\infty}$ is in the interval $[0,1]$.

The second iteration process is referred to as Ishikawa's [5] iteration process which is defined recursively by

$$
\left\{\begin{array}{l}
y_{n}=\beta_{n} x_{n}+\left(1-\beta_{n}\right) T x_{n}, \\
x_{n+1}=\alpha_{n} x_{n}+\left(1-\alpha_{n}\right) T y_{n},
\end{array}\right.
$$

where the initial guess $x_{0}$ is taken in $C$ arbitrarily and $\left\{\alpha_{n}\right\}$ and $\left\{\beta_{n}\right\}$ are sequences in the interval $[0,1]$.

The third one is introduced by Halpern [4] and is defined as follows: Take an initial guess $x_{0} \in C$ arbitrarily and define $\left\{x_{n}\right\}$ recursively by

$$
x_{n+1}=t_{n} u+\left(1-t_{n}\right) T x_{n}, \quad n \geq 0,
$$

where $u \in C$ is an arbitrary (but fixed) element, $\left\{t_{n}\right\}_{n=1}^{\infty}$ is a sequence in the interval $[0,1]$.

In general not much has been known regarding the convergence of the iteration processes (1.1)-(1.3) unless the underlying space $E$ has elegant properties which we briefly mention here.

Reich [11] proved that if $E$ is a uniformly convex Banach space with a Fréchet differentiable norm and if $\left\{\alpha_{n}\right\}$ is chosen such that $\sum_{n=1}^{\infty} \alpha_{n}\left(1-\alpha_{n}\right)=\infty$, then the sequence $\left\{x_{n}\right\}$ defined by (1.1) converges weakly to a fixed point of $T$. However we note that Mann's iterations have only weak convergence even in a Hilbert space [3].

Attempts to modify the Mann iteration method (1.1) so that strong convergence is guaranteed have recently been made. Nakajo and Takahashi [10] proposed the following modification of the Mann iteration (1.1) for a single nonexpansive mapping $T$ in a Hilbert space:

$$
\left\{\begin{array}{l}
x_{0} \in C, \quad \text { arbitrarily chosen } \\
y_{n}=\alpha_{n} x_{n}+\left(1-\alpha_{n}\right) T x_{n}, \\
C_{n}=\left\{z \in C:\left\|y_{n}-z\right\| \leq\left\|x_{n}-z\right\|\right\}, \\
Q_{n}=\left\{z \in C:\left\langle x_{0}-x_{n}, x_{n}-z\right\rangle \geq 0\right\} \\
x_{n+1}=P_{C_{n} \cap Q_{n}} x_{0},
\end{array}\right.
$$


where $P_{K}$ denotes the metric projection from $H$ onto a closed convex subset $K$ of $H$.

However, on the other hand, process (1.2) is indeed more general than process (1.1). But research has been concentrated on the former due probably to the reasons that the formulation of process (1.1) is simpler than that of (1.2) and that a convergence theorem for process (1.1) may lead to a convergence theorem for process (1.2) provided that $\left\{\beta_{n}\right\}$ satisfies certain appropriate conditions. However, the introduction of the process (1.2) has its own right. Actually, process (1.1) may fail to converge while process (1.2) can still converge for a Lipschitz pseudo-contractive mapping in a Hilbert space [1].

Recently, Martinez-Yanes and Xu [9] has adapted the iteration (1.2) in Hilbert space. More precisely, they introduced the following iteration process for a nonexpansive mapping $T$, with $C$ a closed convex bounded subset of a Hilbert space

$$
\left\{\begin{aligned}
x_{0} \in C, \quad \text { chosen arbitrarily } \\
z_{n}=\beta_{n} x_{n}+\left(1-\beta_{n}\right) T x_{n}, \\
y_{n}=\alpha_{n} x_{n}+\left(1-\alpha_{n}\right) T z_{n}, \\
C_{n}=\left\{z \in C:\left\|y_{n}-z\right\|^{2} \leq\left\|x_{n}-z\right\|^{2}\right. \\
\quad+\left(1-\alpha_{n}\right)\left(\left\|z_{n}\right\|^{2}-\|x\|^{2}+2\left\langle x_{n}-z_{n}, v\right)\right\} \\
Q_{n}=\left\{z \in C:\left\langle x_{0}-x_{n}, x_{n}-z\right\rangle \geq 0\right\} \\
x_{n+1}=P_{C_{n} \cap Q_{n}} x_{0},
\end{aligned}\right.
$$

and also they adapted (1.3) in a Hilbert space. More precisely, they defined a sequence $\left\{x_{n}\right\}$ recursively by

$$
\left\{\begin{array}{l}
x_{0} \in C, \quad \text { chosen arbitrarily } \\
y_{n}=\alpha_{n} x_{0}+\left(1-\alpha_{n}\right) T x_{n}, \\
C_{n}=\left\{z \in C:\left\|y_{n}-z\right\|^{2} \leq\left\|x_{n}-z\right\|^{2}+\alpha_{n}\left(\left\|x_{0}\right\|^{2}+2\left\langle x_{n}-x_{0}, z\right)\right\}\right. \\
Q_{n}=\left\{z \in C:\left\langle x_{0}-x_{n}, x_{n}-z\right\rangle \geq 0\right\} \\
x_{n+1}=P_{C_{n} \cap Q_{n}} x_{0} .
\end{array}\right.
$$

In [6] Kim and $\mathrm{Xu}$ also adapt the iteration (1.1) to asymptotically nonexpansive mappings. More precisely, they introduced the following iteration process for asymptotically nonexpansive mappings $T$, with $C$ a closed convex bounded subset of a Hilbert space:

$$
\left\{\begin{array}{l}
x_{0} \in C, \text { arbitrarily chosen } \\
y_{n}=\alpha_{n} x_{n}+\left(1-\alpha_{n}\right) T^{n} x_{n}, \\
C_{n}=\left\{z \in C:\left\|y_{n}-z\right\|^{2} \leq\left\|x_{n}-z\right\|^{2}+\theta_{n}\right\} \\
Q_{n}=\left\{z \in C:\left\langle x_{0}-x_{n}, x_{n}-z\right\rangle \geq 0\right\}, \\
x_{n+1}=P_{C_{n} \cap Q_{n}} x_{0},
\end{array}\right.
$$


where

$$
\theta_{n}=\left(1-\alpha_{n}\right)\left(k_{n}^{2}-1\right)(\operatorname{diam} C)^{2} \rightarrow 0 \quad \text { as } n \rightarrow \infty .
$$

The purpose of this paper is to employ Nakajo and Takahashi's [10] idea to modify process (1.2) and (1.3) to have strong convergence theorems for asymptotically nonexpansive mappings. Our results improve and extend the ones announced by Martinez-Yanes and Xu [9] from nonexpansive mappings to asymptotically nonexpansive mappings.

In order to prove our main results, we shall make use of the following Lemmas.

Lemma 1.1(Lin et al. [7]). Let $T$ be an asymptotically nonexpansive mapping defined on a bounded closed convex subset $C$ of a Hilbert space $H$. Assume that $\left\{x_{n}\right\}$ is a sequence in $C$ with the properties $(i) x_{n} \rightarrow x_{0}$ and (ii) $T x_{n}-x_{n} \rightarrow 0$, then $x_{0} \in F(T)$.

Lemma 1.2 Let $K$ be a closed convex subset of real Hilbert space $H$ and let $P_{K}$ be the metric projection from $H$ onto $K\left(\right.$ i.e., for $x \in H, P_{k}$ is the only point in $K$ such that $\left.\left\|x-P_{k} x\right\|=\inf \{\|x-z\|: z \in K\}\right)$. Given $x \in H$ and $z \in K$. Then $z=P_{K} x$ if and only if there holds the relations:

$$
\langle x-z, y-z\rangle \leq 0 \quad \text { for all } y \in K .
$$

\section{Main Results}

Theorem 2.1 Let $C$ be a bounded closed convex subset of a Hilbert space $H$ and let $T: C \rightarrow C$ be an asymptotically nonexpansive mapping with a sequence $\left\{k_{n}\right\}$ such that $k_{n} \rightarrow 1$ as $n \rightarrow \infty$. Assume that $\left\{\alpha_{n}\right\}$ is a sequence in $(0,1)$ such that $\alpha_{n} \leq 1-\delta$ for all $n$ and for some $\delta \in(0,1]$ and $\beta_{n} \rightarrow 1$. Define a sequence $\left\{x_{n}\right\}$ in $C$ by the following algorithm:

$$
\left\{\begin{aligned}
x_{0} \in C, \quad \text { arbitrarily chosen } \\
z_{n}=\beta_{n} x_{n}+\left(1-\beta_{n}\right) T^{n} x_{n}, \\
y_{n}=\alpha_{n} x_{n}+\left(1-\alpha_{n}\right) T^{n} z_{n}, \\
C_{n}=\left\{v \in C:\left\|y_{n}-v\right\|^{2} \leq\left\|x_{n}-v\right\|^{2}\right. \\
\left.\quad \quad\left(1-\alpha_{n}\right)\left[k_{n}^{2}\left\|z_{n}\right\|^{2}-\left\|x_{n}\right\|^{2}+\left(k_{n}^{2}-1\right) M+2\left\langle x_{n}-k_{n}^{2} z_{n}, v\right\rangle\right]\right\} \\
Q_{n}=\left\{v \in C:\left\langle x_{0}-x_{n}, x_{n}-v\right\rangle \geq 0\right\}, \\
x_{n+1}=P_{C_{n} \cap Q_{n}} x_{0},
\end{aligned}\right.
$$

where $M$ is a appropriate constant such that $M>\|v\|^{2}$ for each $v \in C_{n}$, then $\left\{x_{n}\right\}$ converges to $P_{F(T)} x_{0}$.

Proof. First note that $T$ has a fixed point in C [2]; that is, $F(T)$ is nonempty. It 
follows from the Lemma 1.3 of [9] that $C$ is convex. Next, we show that $F(T) \subset C_{n}$ for all $n$. Indeed, we have, for all $p \in F(T)$,

$$
\begin{aligned}
\left\|y_{n}-p\right\|^{2}= & \left\|\alpha_{n}\left(x_{n}-p\right)+\left(1-\alpha_{n}\right)\left(T^{n} z_{n}-p\right)\right\|^{2} \\
\leq & \alpha_{n}\left\|x_{n}-p\right\|^{2}+\left(1-\alpha_{n}\right) k_{n}^{2}\left\|z_{n}-p\right\|^{2} \\
= & \left\|x_{n}-p\right\|^{2}+\left(1-\alpha_{n}\right)\left(k_{n}^{2}\left\|z_{n}-p\right\|^{2}-\left\|x_{n}-p\right\|^{2}\right) \\
\leq & \left(1-\alpha_{n}\right)\left[k_{n}^{2}\left\|z_{n}\right\|^{2}-\left\|x_{n}\right\|^{2}+\left(k_{n}^{2}-1\right) M+2\left\langle x_{n}-k_{n}^{2} z_{n}, p\right\rangle\right] \\
& +\left\|x_{n}-p\right\|^{2} .
\end{aligned}
$$

So $p \in C_{n}$ for all $n$. Next we show that

$$
F(T) \subset Q_{n} \text { for all } n \geq 0 .
$$

We prove this by induction. For $n=0$, we have $F(T) \subset C=Q_{0}$. Assume that $F(T) \subset Q_{n}$. Since $x_{n+1}$ is the projection of $x_{0}$ onto $C_{n} \cap Q_{n}$, by Lemma 1.2 we have

$$
\left\langle x_{0}-x_{n+1}, x_{n+1}-z\right\rangle \geq 0 \quad \forall z \in C_{n} \cap Q_{n} .
$$

As $F(T) \subset C_{n} \cap Q_{n}$ by the induction assumptions, the last inequality holds, in particular, for all $z \in F(T)$. this together with the definition of $Q_{n+1}$ implies that $F(T) \subset Q_{n+1}$. Hence (2.2) holds for all $n \geq 0$. In order to prove $\lim _{n \rightarrow \infty}\left\|x_{n+1}-x_{n}\right\|=$ 0 , from the definition of $Q_{n}$ we have $x_{n}=P_{Q_{n}} x_{0}$ which together with the fact that $x_{n+1} \in C_{n} \cap Q_{n} \subset Q_{n}$ implies that

$$
\left\|x_{0}-x_{n}\right\| \leq\left\|x_{0}-x_{n+1}\right\| .
$$

This shows that the sequence $\left\{x_{n}-x_{0}\right\}$ is nondecreasing. Since $C$ is bounded, we obtain that $\lim _{n \rightarrow \infty}\left\|x_{n}-x_{0}\right\|$ exists. Notice again that $x_{n}=P_{Q_{n}} x_{0}$ and $x_{n+1} \in Q_{n}$ which give that $\left\langle x_{n+1}-x_{n}, x_{n}-x_{0}\right\rangle \geq 0$. Therefore, we have

$$
\begin{aligned}
\left\|x_{n+1}-x_{n}\right\|^{2} & =\left\|\left(x_{n+1}-x_{0}\right)-\left(x_{n}-x_{0}\right)\right\|^{2} \\
& \leq\left\|x_{n+1}-x_{0}\right\|^{2}-\left\|x_{n}-x_{0}\right\|^{2}-2\left\langle x_{n+1}-x_{n}, x_{n}-x_{0}\right\rangle \\
& \leq\left\|x_{n+1}-x_{0}\right\|^{2}-\left\|x_{n}-x_{0}\right\|^{2} .
\end{aligned}
$$

It follows that

$$
\left\|x_{n}-x_{n+1}\right\| \rightarrow 0, \quad \text { as } n \rightarrow 0 .
$$

On the other hand, It follows from $x_{n+1} \in C_{n}$ that

$$
\begin{aligned}
\left\|y_{n}-x_{n+1}\right\|^{2} \leq & \left(1-\alpha_{n}\right)\left[k_{n}^{2}\left\|z_{n}\right\|^{2}-\left\|x_{n}\right\|^{2}+\left(k_{n}^{2}-1\right) M+2\left\langle x_{n}-k_{n}^{2} z_{n}, x_{n+1}\right\rangle\right] \\
& +\left\|x_{n}-x_{n+1}\right\|^{2} .
\end{aligned}
$$

However, since $\lim _{n \rightarrow \infty} \beta_{n}=1$ and $\left\{x_{n}\right\}$ is bounded, we obtain

$$
\left\|z_{n}-x_{n}\right\|=\left(1-\beta_{n}\right)\left\|x_{n}-T^{n} x_{n}\right\| \rightarrow 0, \quad \text { as } n \rightarrow \infty .
$$


Notice that

$$
\begin{aligned}
& k_{n}^{2}\left\|z_{n}\right\|^{2}-\left\|x_{n}\right\|^{2}+\left(k_{n}^{2}-1\right) M+2\left\langle x_{n}-k_{n}^{2} z_{n}, x_{n+1}\right\rangle \\
= & k_{n}^{2}\left\|z_{n}\right\|^{2}-k_{n}^{2}\left\|x_{n}\right\|^{2}+2\left\langle x_{n}-k_{n}^{2} z_{n}, x_{n+1}\right\rangle+\left(k_{n}^{2}-1\right)\left\|x_{n}\right\|^{2}+\left(k_{n}^{2}-1\right) M \\
= & k_{n}^{2}\left\|z_{n}-x_{n}\right\|^{2}+2\left\langle x_{n}-k_{n}^{2} z_{n}, x_{n+1}-x_{n}\right\rangle-\left(k_{n}^{2}-1\right)\left\|x_{n}\right\|^{2}+\left(k_{n}^{2}-1\right) M \rightarrow 0 .
\end{aligned}
$$

Therefore, it follows from (2.3) and (2.4) that

$$
\left\|y_{n}-x_{n+1}\right\| \rightarrow 0 \text {. }
$$

It follows from (2.3), (2.5) that

$$
\left\|y_{n}-x_{n}\right\| \leq\left\|x_{n}-x_{n+1}\right\|+\left\|x_{n+1}-y_{n}\right\| \rightarrow 0 .
$$

Again, Noticing that $T^{n} z_{n}=y_{n}-\alpha_{n}\left\|x_{n}-T^{n} z_{n}\right\|$, we have

$$
\left\|x_{n}-T^{n} z_{n}\right\| \leq\left\|y_{n}-x_{n}\right\|+\alpha_{n}\left\|x_{n}-T^{n} z_{n}\right\| .
$$

It follows that

$$
\left\|x_{n}-T^{n} z_{n}\right\| \leq \frac{1}{1-\alpha_{n}}\left\|x_{n}-y_{n}\right\| .
$$

Since $\alpha_{n} \leq 1-\delta$, we have

$$
\left\|x_{n}-T^{n} x_{n}\right\| \leq\left\|x_{n}-T^{n} z_{n}\right\|+\left\|T^{n} z_{n}-T^{n} x_{n}\right\| \leq \frac{1}{\delta}\left\|y_{n}-x_{n}\right\|+k_{n}\left\|z_{n}-x_{n}\right\| .
$$

Therefore, It follows from (2.4) and (2.6) that

$$
\left\|x_{n}-T^{n} x_{n}\right\| \rightarrow 0 .
$$

Putting $\bar{k}=\sup \left\{k_{n}: n \geq 1\right\}<\infty$, we obtain

$$
\begin{aligned}
\left\|T x_{n}-x_{n}\right\| \leq & \left\|T x_{n}-T^{n+1} x_{n}\right\|+\left\|T^{n+1} x_{n}-T^{n+1} x_{n+1}\right\| \\
& +\left\|T^{n+1} x_{n+1}-x_{n+1}\right\|+\left\|x_{n+1}-x_{n}\right\| \\
\leq & \bar{k}\left\|x_{n}-T^{n} x_{n}\right\|+(1+\bar{k})\left\|x_{n}-x_{n+1}\right\| \\
& +\left\|T^{n+1} x_{n+1}-x_{n+1}\right\|,
\end{aligned}
$$

which implies that

$$
\left\|T x_{n}-x_{n}\right\| \rightarrow 0
$$

Assume that $\left\{x_{n_{i}}\right\}$ is a subsequence of $\left\{x_{n}\right\}$ such that $x_{n_{i}} \rightarrow \tilde{x}$. by Lemma 1.1 we have $\tilde{x} \in F(T)$. Next we show that $\tilde{x}=P_{F(T)} x_{0}$ and convergence is strong. Put $\bar{x}=P_{F(T)} x_{0}$ and consider the sequence $\left\{x_{0}-x_{n_{i}}\right\}$. Then we have $x_{0}-x_{n_{i}} \rightarrow x_{0}-\tilde{x}$ and by the weak lower semicontinuity of the norm and by the fact that $\left\|x_{0}-x_{n+1}\right\| \leq$ $\left\|x_{0}-\bar{x}\right\|$ for all $n \geq 0$ which is implied by the fact that $x_{n+1}=P_{C_{n} \cap Q_{n}} x_{0}$, we have

$$
\left\|x_{0}-\bar{x}\right\| \leq\left\|x_{0}-\tilde{x}\right\| \leq \liminf _{i \rightarrow \infty}\left\|x_{0}-x_{n_{i}}\right\| \leq \limsup _{i \rightarrow \infty}\left\|x_{0}-x_{n_{i}}\right\| \leq\left\|x_{0}-\bar{x}\right\| .
$$


This gives that

$$
\left\|x_{0}-\bar{x}\right\|=\left\|x_{0}-\tilde{c}\right\| \quad \text { and } \quad\left\|x_{0}-x_{n_{i}}\right\| \rightarrow\left\|x_{0}-\bar{x}\right\|
$$

It follows that $x_{0}-x_{n_{i}} \rightarrow x_{0}-\bar{x}$; hence, $x_{n_{i}} \rightarrow \bar{x}$. since $\left\{x_{n_{i}}\right\}$ is an arbitrary subsequence of $\left\{x_{n}\right\}$, we conclude that $x_{n} \rightarrow \bar{x}$. The proof is completed.

Theorem 2.2 Let $C$ be a bounded closed convex subset of a Hilbert space $H$ and let $T: C \rightarrow C$ be an asymptotically nonexpansive mapping with a sequence $\left\{k_{n}\right\}$ such that $k_{n} \rightarrow 1$ as $n \rightarrow \infty$. Assume that $\left\{\alpha_{n}\right\}$ is a sequence in $(0,1)$ such that $\alpha_{n} \rightarrow 0$ as $n \rightarrow \infty$. Define a sequence $\left\{x_{n}\right\}$ in $C$ by the following algorithm :

$$
\left\{\begin{array}{l}
x_{0} \in C, \quad \text { arbitrarily chosen } \\
y_{n}=\alpha_{n} x_{0}+\left(1-\alpha_{n}\right) T^{n} x_{n}, \\
C_{n}=\left\{v \in C:\left\|y_{n}-v\right\|^{2} \leq\left\|x_{n}-v\right\|^{2}+\left(k_{n}^{2}-1-\alpha_{n} k_{n}^{2}\right)\left\|x_{n}\right\|^{2}\right. \\
\left.\quad+\alpha_{n}\left\|x_{0}\right\|^{2}-2\left\langle\alpha_{n} x_{0}+\left(k_{n}^{2}-1-\alpha_{n} k_{n}^{2}\right) x_{n}, v\right\rangle+\left(1-\alpha_{n}\right)\left(k_{n}^{2}-1\right) M\right\}, \\
Q_{n}=\left\{v \in C:\left\langle x_{0}-x_{n}, x_{n}-v\right\rangle \geq 0\right\}, \\
x_{n+1}=P_{C_{n} \cap Q_{n}} x_{0},
\end{array}\right.
$$

where $M$ is a appropriate constant such that $M>\|v\|^{2}$ for each $v \in C_{n}$, then $\left\{x_{n}\right\}$ converges to $P_{F(T)} x_{0}$.

Proof. First note that $T$ has a fixed point in $\mathrm{C}[2]$; that is, $F(T)$ is nonempty. It follows from the Lemma 1.3 of [9] that $C$ is convex. Next, we show that $F(T) \subset C_{n}$ for all $n$. Indeed, we have, for all $p \in F(T)$,

$$
\begin{aligned}
\left\|y_{n}-p\right\|^{2}= & \left\|\alpha_{n}\left(x_{0}-p\right)+\left(1-\alpha_{n}\right)\left(T^{n} x_{n}-p\right)\right\|^{2} \\
\leq & \alpha_{n}\left\|x_{0}-p\right\|^{2}+\left(1-\alpha_{n}\right) k_{n}^{2}\left\|x_{n}-p\right\|^{2} \\
= & \left\|x_{n}-p\right\|^{2}+\left(k_{n}^{2}-1-\alpha_{n} k_{n}^{2}\right)\left\|x_{n}-p\right\|^{2}+\alpha_{n}\left\|x_{0}-p\right\|^{2} \\
= & \left\|x_{n}-p\right\|^{2}+\left(k_{n}^{2}-1-\alpha_{n} k_{n}^{2}\right)\left\|x_{n}\right\|^{2}+\alpha_{n}\left\|x_{0}\right\|^{2} \\
& -2\left\langle\alpha_{n} x_{0}+\left(k_{n}^{2}-1-\alpha_{n} k_{n}^{2}\right) x_{n}, p\right\rangle+\left(1-\alpha_{n}\right)\left(k_{n}^{2}-1\right)\|p\|^{2} \\
\leq & \left\|x_{n}-p\right\|^{2}+\left(k_{n}^{2}-1-\alpha_{n} k_{n}^{2}\right)\left\|x_{n}\right\|^{2}+\alpha_{n}\left\|x_{0}\right\|^{2} \\
& -2\left\langle\alpha_{n} x_{0}+\left(k_{n}^{2}-1-\alpha_{n} k_{n}^{2}\right) x_{n}, p\right\rangle+\left(1-\alpha_{n}\right)\left(k_{n}^{2}-1\right) M
\end{aligned}
$$

So $p \in C_{n}$ for all $n$. Next we show that

$$
F(T) \subset Q_{n} \text { for all } n \geq 0 .
$$

We prove this by induction. For $n=0$, we have $F(T) \subset C=Q_{0}$. Assume that $F(T) \subset Q_{n}$. Since $x_{n+1}$ is the projection of $x_{0}$ onto $C_{n} \cap Q_{n}$, by Lemma 1.2 we have

$$
\left\langle x_{0}-x_{n+1}, x_{n+1}-z\right\rangle \geq 0 \quad \forall z \in C_{n} \cap Q_{n} .
$$

As $F(T) \subset C_{n} \cap Q_{n}$ by the induction assumptions, the last inequality holds, in particular, for all $z \in F(T)$. this together with the definition of $Q_{n+1}$ implies that 
$F(T) \subset Q_{n+1}$. Hence (2.8) holds for all $n \geq 0$. In order to prove $\lim _{n \rightarrow \infty}\left\|x_{n+1}-x_{n}\right\|=$ 0 , from the definition of $Q_{n}$ we have $x_{n}=P_{Q_{n}} x_{0}$ which together with the fact that $x_{n+1} \in C_{n} \cap Q_{n} \subset Q_{n}$ implies that

$$
\left\|x_{0}-x_{n}\right\| \leq\left\|x_{0}-x_{n+1}\right\| .
$$

This shows that the sequence $\left\{x_{n}-x_{0}\right\}$ is nondecreasing. Since $C$ is bounded, we obtain that $\lim _{n \rightarrow \infty}\left\|x_{n}-x_{0}\right\|$ exists. Notice again that $x_{n}=P_{Q_{n}} x_{0}$ and $x_{n+1} \in Q_{n}$ which give that $\left\langle x_{n+1}-x_{n}, x_{n}-x_{0}\right\rangle \geq 0$. Therefore, we have

$$
\begin{aligned}
\left\|x_{n+1}-x_{n}\right\|^{2} & =\left\|\left(x_{n+1}-x_{0}\right)-\left(x_{n}-x_{0}\right)\right\|^{2} \\
& \leq\left\|x_{n+1}-x_{0}\right\|^{2}-\left\|x_{n}-x_{0}\right\|^{2}-2\left\langle x_{n+1}-x_{n}, x_{n}-x_{0}\right\rangle \\
& \leq\left\|x_{n+1}-x_{0}\right\|^{2}-\left\|x_{n}-x_{0}\right\|^{2} .
\end{aligned}
$$

It follows that

$$
\left\|x_{n}-x_{n+1}\right\| \rightarrow 0, \quad \text { as } n \rightarrow 0 .
$$

On the other hand, It follows from $x_{n+1} \in C_{n}$ that

$$
\begin{aligned}
\left\|y_{n}-x_{n+1}\right\|^{2} \leq & \left\|x_{n}-x_{n+1}\right\|^{2}+\left(k_{n}^{2}-1-\alpha_{n} k_{n}^{2}\right)\left\|x_{n}\right\|^{2}+\alpha_{n}\left\|x_{0}\right\|^{2} \\
& -2\left\langle\alpha_{n} x_{0}+\left(k_{n}^{2}-1-\alpha_{n} k_{n}^{2}\right) x_{n}, x_{n+1}\right\rangle+\left(1-\alpha_{n}\right)\left(k_{n}^{2}-1\right) M .
\end{aligned}
$$

However, since (2.9), $\lim _{n \rightarrow \infty} \alpha_{n}=0$ and $\lim _{n \rightarrow \infty} k_{n}=1$, we obtain

$$
\left\|y_{n}-x_{n+1}\right\| \rightarrow 0
$$

It follows from (2.9), (2.10) that

$$
\left\|y_{n}-x_{n}\right\| \leq\left\|x_{n}-x_{n+1}\right\|+\left\|x_{n+1}-y_{n}\right\| \rightarrow 0 .
$$

Again, Noticing that $y_{n}=\alpha_{n} x_{0}-\left(1-\alpha_{n}\right) T^{n} x_{n}$, we have

$$
\begin{aligned}
\left\|x_{n}-T^{n} x_{n}\right\| & \leq \frac{1}{1-\alpha_{n}}\left\|\left(y_{n}-x_{n}\right)+\alpha_{n}\left(x_{n}-x_{0}\right)\right\| \\
& \leq \frac{1}{1-\alpha_{n}}\left(\left\|y_{n}-x_{n}\right\|+\alpha_{n}\left\|x_{n}-x_{0}\right\|\right) .
\end{aligned}
$$

Since $\lim _{n \rightarrow \infty} \alpha_{n}=0$ and (2.11), we have

$$
\left\|x_{n}-T^{n} x_{n}\right\| \rightarrow 0 .
$$

Putting $\bar{k}=\sup \left\{k_{n}: n \geq 1\right\}<\infty$, we obtain

$$
\begin{aligned}
\left\|T x_{n}-x_{n}\right\| \leq & \left\|T x_{n}-T^{n+1} x_{n}\right\|+\left\|T^{n+1} x_{n}-T^{n+1} x_{n+1}\right\| \\
& +\left\|T^{n+1} x_{n+1}-x_{n+1}\right\|+\left\|x_{n+1}-x_{n}\right\| \\
\leq & \bar{k}\left\|x_{n}-T^{n} x_{n}\right\|+(1+\bar{k})\left\|x_{n}-x_{n+1}\right\| \\
& +\left\|T^{n+1} x_{n+1}-x_{n+1}\right\|,
\end{aligned}
$$


which implies that

$$
\left\|T x_{n}-x_{n}\right\| \rightarrow 0 \text {. }
$$

Using the methods of Theorem 2.1, we can get the desired conclusions easily. The proof is completed.

\section{Applications}

Theorem 3.1(Martinez-Yanes and $\mathrm{Xu}[11])$. Let $C$ be a nonempty closed convex subset of a Hilbert space $H$ and let $T: C \rightarrow C$ be a nonexpansive mapping such that $F(T) \neq \emptyset$. Assume that $\left\{\alpha_{n}\right\}_{n=0}^{\infty}$ and $\left\{\beta_{n}\right\}_{n=0}^{\infty}$ are sequences in $(0,1)$ such that $\lim _{n \rightarrow \infty} \alpha_{n} \leq 1-\delta$ for some $\delta \in(0,1]$ and $\limsup _{n \rightarrow \infty} \beta_{n}=1$. Define a sequence $\left\{x_{n}\right\}$ in $C$ by the following algorithm

$$
\left\{\begin{aligned}
x_{0} \in & C, \quad \text { arbitrarily chosen } \\
z_{n}= & \beta_{n} x_{n}+\left(1-\beta_{n}\right) T x_{n}, \\
y_{n}= & \alpha_{n} x_{n}+\left(1-\alpha_{n}\right) T z_{n}, \\
C_{n}= & \left\{v \in C:\left\|y_{n}-v\right\|^{2} \leq\left\|x_{n}-v\right\|^{2}+\left(1-\alpha_{n}\right)\left(\left\|z_{n}\right\|^{2}\right.\right. \\
& \left.\left.\quad-\left\|x_{n}\right\|^{2}+2\left\langle x_{n}-z_{n}, v\right\rangle\right)\right\}, \\
Q_{n}= & \left\{v \in C:\left\langle x_{0}-x_{n}, x_{n}-v\right\rangle \geq 0\right\}, \\
x_{n+1}= & P_{C_{n} \cap Q_{n}} x_{0},
\end{aligned}\right.
$$

Then $\left\{x_{n}\right\}$ converges to $q=P_{F(T)} x_{0}$.

Proof. Since $T$ is asymptotically nonexpansive which is also nonexpansive when $\left\{k_{n}\right\}=1$. By using Theorem 2.1, we can obtain the desired conclusion easily. This completes the proof.

Theorem 3.2(Martinez-Yanes and $\mathrm{Xu}[11])$. Let $H$ be a real Hilbert space, $C$ a closed convex subset of $H$ and $T: C \rightarrow C$ a nonexpansive mapping such that $F(T) \neq \emptyset$. Assume that $\alpha_{n} \subset(0,1)$ is chosen such that $\lim _{n \rightarrow \infty} \alpha_{n}=0$. Then the sequence $\left\{x_{n}\right\}_{n=0}^{\infty}$ generated by

$$
\left\{\begin{array}{l}
x_{0} \in C, \quad \text { arbitrarily chosen } \\
y_{n}=\alpha_{n} x_{0}+\left(1-\alpha_{n}\right) T x_{n}, \\
C_{n}=\left\{z \in C:\left\|y_{n}-z\right\|^{2} \leq\left\|x_{n}-z\right\|^{2}+\alpha_{n}\left(\left\|x_{0}\right\|^{2}+2\left\langle x_{n}-x_{0}, z\right\rangle\right)\right\} \\
Q_{n}=\left\{z \in C:\left\langle x_{0}-x_{n}, x_{n}-z\right\rangle \geq 0\right\} \\
x_{n+1}=P_{C_{n} \cap Q_{n}} x_{0}
\end{array}\right.
$$

converges strongly to $P_{F(T)} x_{0}$.

Proof. Since $T$ is asymptotically nonexpansive which is also nonexpansive when $\left\{k_{n}\right\}=1$. By using Theorem 2.2, we can obtain the desired conclusion easily. This completes the proof. 
Acknowledgment. The author thanks the referee for his/her comments and suggestions which improved the presentation of this manuscript.

\section{References}

[1] C. E. Chidume and S. A. Mutangadura, An example on the Mann iteration method for Lipschitz pseudocontractions, Proc. Am. Math. Soc., 129(2001), 2359-2363.

[2] K. Goebel and W. A. Kirk, A fixed point theorem for asymptotically nonexpansive mappings, Proc. Am. Math. Soc., 35(1972), 171-174.

[3] A. Genel and J. Lindenstrass, An example concerning fixed points, Israel J. Math., 22(1975), 81-86.

[4] B. Halpern, Fixed points of nonexpanding maps, Bull. Am. Math. Soc., 73(1967), 957-961.

[5] S. Ishikawa, Fixed points by a new iteration medthod, Proc. Am. Math. Soc., 44(1974), 147-150.

[6] T. H. Kim and H. K. Xu, Strong convergence of modified mann iterations for asymptotically nonexpansive mappings and semigroups, Nonlinear Anal., 64(2006), 1140-1152.

[7] P. K. Lin, K. K. Tan and H. K. Xu, Demiclosedness principle and asymptotically nonexpansive mappings, Nonlinear Anal., 24(1995), 929-946.

[8] W. R. Mann, Mean value methods in iteration, Proc. Amer. Math. Soc., 4(1953), 506-510.

[9] C. Martinez-Yanes and H. K Xu, Strong convergence of the CQ method for fixed point iteration processes, Nonlinear Anal., 64(2006), 2400-2411.

[10] K. Nakajo and W. Takahashi, Strong convergence theorems for nonexpansive mappings and nonexpansive semigroups, J. Math. Anal. Appl., 279(2003), 372-379.

[11] S. Reich, Weak convergence theorems for nonexpansive mappings in Banach spaces, J. Math. Anal. Appl., 67(1979), 274-276. 